\begin{tabular}{c}
$\begin{array}{c}\text { Ambiente \& Água - An Interdisciplinary Journal of Applied Science } \\
\text { ISSN 1980-993X - doi:10.4136/1980-993X } \\
\text { www.ambi-agua.net } \\
\text { E-mail: ambi-agua@agro.unitau.br }\end{array}$ \\
\hline
\end{tabular}

\title{
Viabilidade do uso de água residuária tratada na irrigação da cultura do rabanete (Raphanus sativus L.)
}

\author{
doi: 10.4136/ambi-agua.1220
}

Received: 20 Oct 2013; Accepted: 08 Mar 2014

\author{
Iasmine Louise de Almeida Dantas ${ }^{1 *}$; Gregorio Guirado Faccioli ${ }^{1}$; \\ Luciana Coêlho Mendonça ${ }^{2}$; Tatiana Pacheco Nunes ${ }^{3}$; \\ Pedro Roberto Almeida Viegas ${ }^{1}$; \\ Larissa Oliveira Gama de Santana ${ }^{1}$ \\ ${ }^{1}$ Universidade Federal de Sergipe (UFS) - São Cristovão, SE, Brasil \\ Departamento de Engenharia Agronômica (DEA) \\ ${ }^{2}$ Universidade Federal de Sergipe (UFS) - São Cristovão, SE, Brasil \\ Departamento de Engenharia Civil (DEC) \\ ${ }^{3}$ Universidade Federal de Sergipe (UFS) - São Cristovão, SE, Brasil \\ Departamento de Engenharia de Alimentos \\ *Autor correspondente: e-mail: iasminedantas@gmail.com, \\ gregorioufs@gmail.com, lumendon@uol.com.br, tpnunes@uol.com.br, \\ pviegas@ufs.br, larissa.ogs@gmail.com
}

\section{RESUMO}

A utilização de água residuária tratada para irrigação pode se tornar uma alternativa para regiões que enfrentam escassez de água. O presente trabalho teve como objetivo avaliar os efeitos do reuso de efluente doméstico na cultura do rabanete (Raphanus sativus L.). O experimento foi realizado em casa de vegetação do Departamento de Engenharia Agronômica (DEA), localizada na Universidade Federal de Sergipe/Campus de São Cristóvão no período de agosto a setembro de 2011. O efluente foi coletado na Estação de Tratamento de Esgotos (ETE) Rosa Elze, localizada no Município de São Cristóvão/SE. As irrigações foram feitas utilizando-se cinco diluições diferentes. A lâmina de irrigação foi obtida pelo método do Food and Agriculture Organization (FAO) 56. O delineamento experimental utilizado foi inteiramente casualizado (IC), com cinco repetições e duas plantas por parcela útil. Foram avaliados altura, massa seca e fresca da parte aérea; comprimento e massa fresca da raiz; diâmetro do fruto e número de folhas. Os dados obtidos foram submetidos à análise de variância e as médias comparadas pelo teste de Tukey ao nível de 5\% de probabilidade, não havendo diferença significativa. Em relação à qualidade microbiológica do bulbo, realizou-se a enumeração de coliformes termotolerantes, de bactérias aeróbias mesófilas e a pesquisa de Salmonella, os resultados demonstram que o rabanete encontra-se dentro dos padrões estabelecidos pela legislação.

Palavras-chave: efluente, reuso, microbiologia, agricultura.

\section{Viability of using treated wastewater for the irrigation of radish (Raphanus sativus L.)}

\begin{abstract}
The use of treated wastewater for irrigation may become an alternative for regions facing water scarcity. This study aimed to evaluate the effects of wastewater reuse in the cultivation
\end{abstract}


of radish (Raphanus sativus L.). The experiment was conducted in the greenhouse of the Department of Agricultural Engineering (DEA), located at the Federal University of Sergipe/Campus of São Cristóvão from August to September 2011. The effluent was collected at the Sewage Treatment Plant (WWTP) Rosa Elze, located in the municipality of São Cristóvão/SE. Irrigation was performed using five different dilutions, and was accomplished using the method of the Food and Agriculture Organization (FAO) 56. The experimental design was a completely randomized design (CRD) with five replications and two plants per useful plot. The study evaluated height, fresh and dry shoot matter, length and fresh weight of root, fruit diameter and number of leaves. The data were subjected to ANOVA and means were compared by the Tukey test at $5 \%$ probability, with no significant difference. Regarding the microbiological quality of the bulb, the results of the enumeration of coliforms, mesophilic aerobic bacteria and the detection of Salmonella demonstrate that the radish is within the standards established by legislation.

Keywords: effluent, reuse, microbiology, agriculture.

\section{INTRODUÇÃO}

O desenvolvimento agrícola exige novas estratégias, no sentido de potencializar a produtividade e minimizar os riscos na produção. Com o aumento da população mundial, a produção de alimentos com base apenas na estação chuvosa não é suficiente. Um dos importantes desafios da agricultura atual é o aumento da competitividade e qualidade dos produtos, associado à preservação dos recursos hídricos e do meio ambiente, permitindo benefícios sustentáveis nas explorações agrícolas. Neste contexto, é importante avaliar e adequar cada um dos fatores que compõem o sistema de produção, incluindo a eficiência e o manejo da água de irrigação.

Nas regiões áridas e semiáridas, a água se tornou um fator limitante para o desenvolvimento urbano, industrial e agrícola. Planejadores e entidades gestoras de recursos hídricos procuram, continuadamente, novas fontes de recursos para complementar à pequena disponibilidade hídrica ainda disponível (Hespanhol, 2003).

Por meio da irrigação, pode-se intensificar a produção agrícola, regularizando, ao longo do ano, as disponibilidades e os estoques de alimentos, uma vez que essa prática permite uma produção na contra estação. A atividade de irrigação é a maior consumidora de água entre os diversos usos desse recurso natural. Dentro dela, os consumos específicos variam bastante, dependendo do método de irrigação empregado. A natureza do solo, o tipo de requerimentos das diferentes culturas e os índices de evaporação locais são elementos importantes para definir o consumo de água para irrigação (Hespanhol, 2002).

A irrigação não pode e não deve competir com o uso da água destinada ao abastecimento doméstico, que sempre será prioridade. Pela Constituição Brasileira, a ordem de prioridade do uso da água é a seguinte: consumo humano, indústria e, por fim, irrigação. Assim, as águas utilizadas em irrigação são cada vez mais escassas e de pior qualidade. Essa realidade demanda uma busca de adaptação das técnicas de irrigação existentes e amplamente difundidas às condições atuais e futuras de escassez de água. Diante desse panorama é clara a necessidade de se utilizar esse recurso natural com maior racionalidade, seja através de técnicas que permitam um aproveitamento mais eficiente da água em diversas atividades humanas, como a irrigação ou pela busca de fontes alternativas de água (Duarte, 2006).

Para determinar as necessidades hídricas das culturas, o método mais usual está baseado na estimativa da evapotranspiração da cultura (ETc), que envolve um processo em duas etapas. Na primeira, estima-se a evapotranspiração de referência (ETo), geralmente utilizando uma equação empírica (determinação indireta). Na segunda, a ETc é obtida ao multiplicar 
ETo por um coeficiente de cultura $(\mathrm{kc})$ que integra as características da cultura e do clima local (Doorenbos e Pruitt, 1977; Allen ,1998).

Para entender e poder predizer a quantidade de água necessária em uma irrigação de forma precisa e acurada, o contínuo solo-planta-atmosfera deve ser considerado como um sistema dinâmico, fisicamente integrado, onde os processos de transporte ocorrem interativamente. Neste, os fatores meteorológicos de superfície controlam a força de demanda hídrica, daí um sistema de monitoramento e controle baseado em medições, em tempo real, de parâmetros ligados ao contínuo solo-planta-atmosfera devem ser usados para determinar as necessidades hídricas das culturas e estabelecer estratégias de manejo de irrigação, visando otimizar e racionalizar a utilização da água e da energia com melhoria de produtividade das culturas (Faria, 1998).

A falta de recursos hídricos e o aumento dos conflitos pelo uso da água geraram a emergência da conservação e do tratamento e reuso, como componentes formais da gestão de recursos hídricos. Os benefícios inerentes à utilização de água recuperada para usos benéficos, ao contrário de disposição ou descarga, incluem preservação de fontes de qualidade elevada, proteção ambiental e benefícios econômicos e sociais (Asano et al., 2007).

Qualquer que seja a forma de reuso empregada é fundamental observar que os princípios básicos que devem orientar essa prática são: preservação da saúde dos usuários, preservação do meio ambiente, atendimento consistente às exigências de qualidade, relacionadas ao uso pretendido e proteção dos materiais e equipamentos utilizados nos sistemas de reuso (Hespanhol, 2002).

Medeiros et al. (2008) verificaram que a irrigação com esgoto filtrado foi mais efetiva na melhoria do estado nutricional do cafeeiro que a irrigação convencional, revelando que a aplicação controlada de esgoto ao solo é uma alternativa para fertilização das culturas, potencializando a produção de alimentos. E, na irrigação com efluente sanitário tratado por diversas tecnologias de tratamento, Duarte et al. (2008) concluíram que os efluentes utilizados mostraram qualidade física e química adequada para plantas de pimentão.

A quantidade de nitrogênio adicionado ao solo por meio da irrigação com esgoto sanitário pode ser similar ou até mesmo exceder a quantidade aplicada via fertilização nitrogenada recomendada, durante períodos de tempo similares (Feigin et al., 1978 apud Medeiros et al., 2008).

Assim, a fim de assegurar a proteção dos usuários, dos alimentos produzidos e das pessoas envolvidas com os métodos de reuso de esgotos, é necessário avaliar os aspectos sanitários dessas práticas, principalmente quanto à propagação de patógenos (Daltro Filho, 2004).

A Organização Mundial da Saúde - OMS (WHO, 2006) destaca a importância da qualidade biológica dos efluentes utilizados na irrigação, para que se diminua a probabilidade de propagação de patógenos, ocasionando diversas enfermidades, e recomenda que o efluente tratado contenha menos que $10^{3} \mathrm{NMP}$ (Número Mais Provável) por $100 \mathrm{~mL}$ de coliformes termotolerantes e menos que 1 ovo de nematoide por litro para que esse efluente possa ser utilizado na irrigação irrestrita.

Segundo Pelczar Jr. et al. (1997), os micro-organismos estão intimamente associados com a disponibilidade, a abundância e a qualidade do alimento para consumo humano. Os alimentos são facilmente contaminados com micro-organismos no ambiente, durante a manipulação e o processamento. Após ter sido contaminado, o alimento serve como meio para a multiplicação de micro-organismos. Se esses micro-organismos tiverem condições de se multiplicarem, podem mudar as características físicas e químicas do alimento e podem causar sua deterioração. Os micro-organismos no alimento podem também ser responsáveis por intoxicações e infecções. 
As bactérias são os principais micro-organismos constituintes da microbiota em hortaliças. Isso ocorre, pois o valor do $\mathrm{pH}$ encontrado nesse tipo de alimento $(5,0-6,5)$ favorece a multiplicação destes micro-organismos em relação à multiplicação dos bolores e leveduras (King et al., 1991). Dessa forma, a população de micro-organismos mesófilos presente nos vegetais pode ser tão elevada quanto $10^{9} \mathrm{UFC} \mathrm{g}^{-1}$ (Unidade Formadora de Colônia por grama), mas geralmente fica entre $10^{4} \mathrm{e}^{1} 0^{6} \mathrm{UFC} \mathrm{g}^{-1}$. Esta variabilidade ocorre em função das condições climáticas, da presença de animais e de insetos ou da injúria no próprio vegetal (Nguyen e Carlin, 1994).

Os micro-organismos patogênicos e deteriorantes podem contaminar os vegetais durante a pré e pós-colheita. Durante a pré-colheita, os principais focos de contaminação são: o solo, a água de irrigação, a água utilizada para aplicar fungicidas e inseticidas, a poeira, os insetos, a compostagem inadequada, os animais domésticos e selvagens e a manipulação humana. As fontes de contaminação pós-colheita incluem manipulação humana, equipamentos de colheita, embalagens de transporte, animais, insetos, poeira, água de lavagem, gelo, veículos de transporte e equipamentos durante o processo (Brackett, 1999; Beuchat, 2002).

De forma a possibilitar a investigação da irrigação com efluente tratado em um curto período de tempo, foi escolhida a cultura do rabanete que, segundo (Cardoso e Hiraki, 2001), apesar de ser uma cultura de pequena importância em termos de área plantada, é cultivado em grande número de pequenas propriedades dos cinturões verdes das regiões metropolitanas. Uma das vantagens de se cultivar esta espécie é a possibilidade de auferir ganhos durante o tempo transcorrido entre duas outras culturas de ciclo mais longo, pois além de ser relativamente rústica, apresenta ciclo muito curto (cerca de 30 dias), com retorno rápido.

Assim o presente trabalho teve o objetivo de analisar a viabilidade do uso de água residuária na irrigação do rabanete (Raphanus sativus L.).

\section{MATERIAL E MÉTODOS}

O experimento foi realizado em estufa agrícola do Departamento de Engenharia Agronômica (DEA), localizada na Universidade Federal de Sergipe/Campus de São Cristóvão (Figura 1).

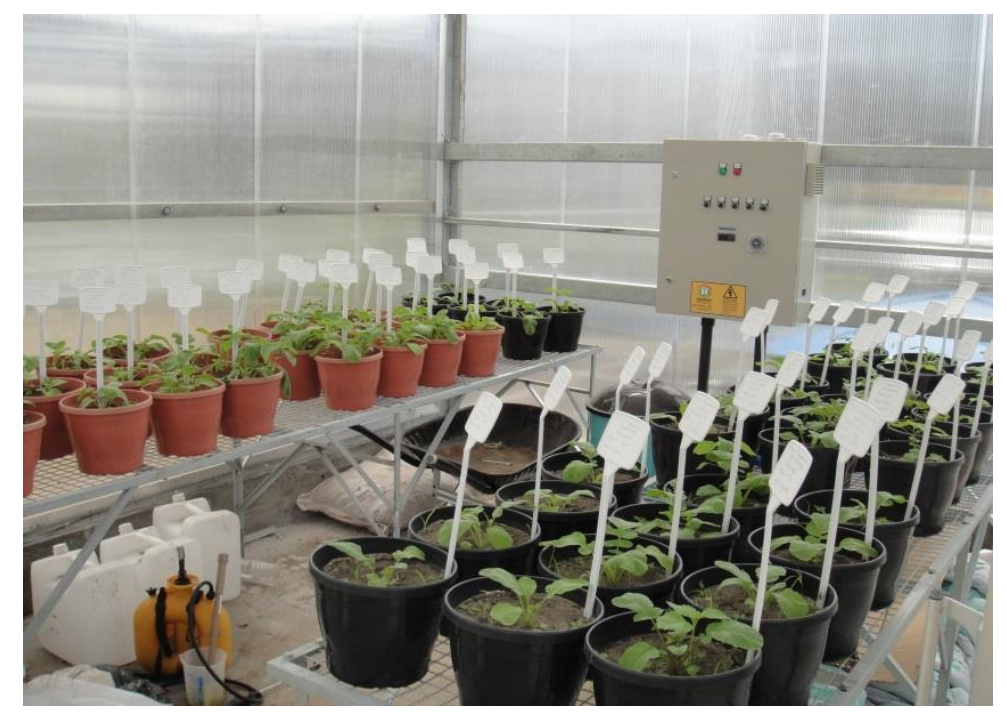

Figura 1. Esquema do experimento na casa de vegetação.

As diluições foram: T1 (100\% de água potável da Companhia de Saneamento de Sergipe - DESO); T2 (100\% de efluente); T3 (50\% de água DESO + 50\% de efluente); T4 ( $25 \%$ de água DESO + 75\% de efluente) e T5 (75\% de água DESO + 25\% de efluente). Foi 
utilizado o delineamento estatístico inteiramente casualizado (IC), com cinco repetições e duas plantas por parcela útil.

A semeadura foi realizada no dia 24/08/2011, utilizando-se sementes de Rabanete (Raphanus sativus L.) produzidas pela empresa Isla; o substrato utilizado foi Terra Vegetal fabricado por Organfert Fertilizantes Orgânicos LTDA- ME, a cultura agrícola foi conduzida em vasos e irrigada diariamente. Aos oito dias após a germinação, foi feito o desbaste das plântulas, quando estas apresentavam o primeiro par de folhas definitivas, deixando aquela mais vigorosa.

O efluente doméstico foi coletado semanalmente da Estação de Tratamento de Esgotos (ETE) Rosa Elze, localizada no Município de São Cristóvão/SE. A estação foi construída na década de 80 para tratar as águas residuárias geradas nos bairros residenciais Rosa Elze e Eduardo Gomes. Esse sistema de tratamento é operado e mantido pela DESO; o mesmo é constituído por cinco lagoas de estabilização em série, sendo duas facultativas e três de maturação, totalizando uma área total de 29.650 metros quadrados.

Inicialmente, o esgoto "in natura", ou seja, sem tratamento, foi coletado em um vasilhame de dois litros e foi encaminhado para análise química e fitossanitária em laboratório do Departamento de Química da Universidade Federal de Sergipe. Para coleta semanal do efluente, foram utilizados vasilhames de vinte litros, utilizados na aplicação das diluições.

Para a estimativa da demanda hídrica da cultura, foi utilizada a metodologia proposta pelo documento FAO 56, ou seja, as variáveis climáticas (temperatura, umidade relativa, radiação e velocidade do vento) foram monitoradas diariamente para dar suporte à estimativa da evapotranspiração de referência pelo método de Penman-Monteith e o coeficiente de cultivo foi estabelecido em função da fase fenológica da cultura.

A colheita foi realizada no dia 26/09/2011. Após a colheita, foram determinadas as características agronômicas (altura da parte aérea - APA, massa seca da parte aérea - MSPA e massa fresca da parte aérea - MFPA, massas fresca da raiz - MFR, diâmetro do bulbo - DB, número de folhas - NF e comprimento da raiz - CR) e microbiológicas do bulbo (enumeração de coliformes termotolerantes, pesquisa de Salmonella e enumeração de bactérias aeróbias mesófilas).

Para a determinação das características agronômicas, as plantas foram lavadas e a medição de altura da parte aérea e comprimento da raiz foram realizadas utilizando-se régua. O diâmetro do bulbo foi estimado utilizando-se um paquímetro. Para obtenção dos valores das massas foi utilizada balança digital do Laboratório de Fisiologia de Pós Colheita, localizado no Departamento de Engenharia Agronômica da Universidade Federal de Sergipe.

As análises microbiológicas foram realizadas no Laboratório de Microbiologia de Alimentos no Departamento de Tecnologia de Alimentos da Universidade Federal de Sergipe.

Foram pesadas $25 \mathrm{~g}$ de cada amostra, totalizando cinco amostras referentes às cinco diluições utilizadas na irrigação. As amostras foram transferidas assepticamente para frascos contendo $225 \mathrm{~mL}$ de água peptonada e em seguida foram preparadas diluições decimais até $10^{-6}$ em água peptonada $0,1 \%$. Foram feitas duplicatas de cada amostra.

Para a análise de coliformes termotolerantes, alíquotas de $1 \mathrm{~mL}$ de cada diluição foram inoculadas em séries de três tubos contendo $9 \mathrm{~mL}$ de caldo lactosado posteriormente, os tubos foram incubados a $35^{\circ} \mathrm{C}$ por 48 horas e os tubos com leitura positiva (turvação e formação de gás), seguiram para os testes confirmativos em caldo $\mathrm{EC}$ a $45^{\circ} \mathrm{C}$ por 48 horas (Kornacki e Johnson, 2001).

Os valores de NMP $\mathrm{g}^{-1}$ foram calculados utilizando-se a tabela de NMP para 3 séries de 3 tubos conforme Swanson et al. (2001).

Em relação à enumeração de mesófilos, a partir de cada diluição selecionada, semeou-se $1 \mathrm{~mL}$ em placas de Petri sobre a qual foi adicionado PCA. Após a completa homogeneização e solidificação do meio, as placas foram incubadas a $37^{\circ} \mathrm{C}$ por $48 \mathrm{~h}$. As placas contendo entre 
25 e 250 colônias foram contadas. Os resultados foram expressos em unidades formadoras de colônias por grama de alimento (UFC g ${ }^{-1}$ ) (Morton, 2001).

$\mathrm{Na}$ etapa de pré-enriquecimento para a análise da pesquisa de Salmonella, $25 \mathrm{~g}$ de amostra foram diluídas em $225 \mathrm{~mL}$ de caldo lactosado que posteriormente foi incubada a $37^{\circ} \mathrm{C}$ por 24 horas. Para o enriquecimento seletivo, após a incubação do pré-enriquecimento, retiraram-se alíquotas de $0,1 \mathrm{~mL}$ e $1.0 \mathrm{~mL}$ do caldolactosado as quais foram adicionadas em dois meios seletivos distintos, Rappaport-Vassiliadis e o caldo Tetrationato a $42^{\circ} \mathrm{C}$ e $37^{\circ} \mathrm{C}$, respectivamente. Em seguida, semeou-se esse inóculo em meio seletivo diferencial de ágar Hektoen Enteric (HE- Oxoid) e ágar Xilose-Lisina Desoxicolato (XLD) e incubados a $37^{\circ} \mathrm{C}$ por 24 horas de forma a obter colônias típicas. As colônias típicas foram confirmadas através de provas bioquímicas.

A análise estatística foi feita utilizando-se o programa de estatística SISVAR da Universidade Federal de Lavras. Os dados foram submetidos à Anova e as médias pelo teste de Tukey, a $5 \%$ de probabilidade.

\section{RESULTADOS E DISCUSSÃO}

Observam-se na Tabela 1 os valores dos parâmetros analisados na água do efluente.

Tabela 1. Análise fisicoquímica do efluente realizada no Laboratório de Química Ambiental da UFS.

\begin{tabular}{c|lcccc}
\hline Data & Amostra & $\mathbf{p H}$ & $\begin{array}{c}\text { N-Total } \\
\left(\mathrm{mg} \mathrm{L}^{-1}\right)\end{array}$ & $\begin{array}{c}\text { Sólidos Totais } \\
\text { Dissolvidos } \\
(\mathrm{ppm})\end{array}$ & $\begin{array}{c}\text { P-Total } \\
\left(\mathrm{mg} \mathrm{L}^{-1}\right)\end{array}$ \\
\hline \multirow{2}{*}{$30 / 08 / 11$} & Entrada* & 7,4 & 82,3 & 183,33 & 18,70 \\
& Saída** & 7,3 & 33,1 & 13,16 & 13,20 \\
\hline \multirow{2}{*}{ 13/09/11 } & Entrada* & 7,5 & 99,6 & 109,52 & 29,90 \\
& Saída** & 7,7 & 26,7 & 466,67 & 14,08 \\
\hline \multirow{2}{*}{ 20/09/11 } & Entrada* & 7,7 & 98,2 & 208,33 & 22,80 \\
& Saída** & 7,7 & 36,1 & 73,33 & 14,80 \\
\hline
\end{tabular}

Nota: "Entrada: valores do afluente coletado na entrada da lagoa de maturação.

***Saída: valores do efluente coletado na saída da lagoa de maturação.

Na Tabela 1, observa-se que o efluente do sistema de lagoas é levemente ácido e que ocorre remoção de nutrientes (nitrogênio e fósforo) e sólidos dissolvidos. Na amostra do efluente de 13/09/11, pode ter ocorrido alguma contaminação da amostra ou ter sido coletada juntamente com algum lodo flotado, ocasionando valor elevado de sólidos. Os nutrientes remanescentes presentes nas amostras do efluente podem vir a beneficiar a necessidade nutricional da cultura irrigada com esse efluente.

Durante a realização deste experimento, Ramiro et al. (2012) analisaram a qualidade do sistema de lagoas de estabilização e verificaram que não foram encontrados ovos de helmintos no efluente do sistema de tratamento, durante o monitoramento microbiológico realizado no período.

Na Tabela 2, são apresentados os resultados das análises agronômicas realizadas no rabanete. 
Tabela 2. Médias das variáveis analisadas.

\begin{tabular}{c|ccccccc}
\hline Diluições & $\begin{array}{c}\text { MFPA } \\
(\mathrm{g})\end{array}$ & $\begin{array}{c}\text { MFR } \\
(\mathrm{g})\end{array}$ & $\begin{array}{c}\text { APA } \\
(\mathrm{cm})\end{array}$ & $\begin{array}{c}\mathbf{C R} \\
(\mathrm{cm})\end{array}$ & $\begin{array}{c}\text { DB } \\
(\mathrm{cm})\end{array}$ & $\mathbf{N F}$ & $\begin{array}{c}\text { MSPA } \\
(\mathrm{g})\end{array}$ \\
\hline $\mathbf{1}$ & $8,75 \mathrm{a}$ & $12,11 \mathrm{a}$ & $19,37 \mathrm{a}$ & $9,52 \mathrm{a}$ & $2,76 \mathrm{a}$ & $6,3 \mathrm{a}$ & $0,8175 \mathrm{a}$ \\
$\mathbf{2}$ & $10,26 \mathrm{a}$ & $16,39 \mathrm{a}$ & $19,69 \mathrm{a}$ & $9,11 \mathrm{a}$ & $3,04 \mathrm{a}$ & $6,4 \mathrm{a}$ & $0,8395 \mathrm{a}$ \\
$\mathbf{3}$ & $12,06 \mathrm{a}$ & $14,19 \mathrm{a}$ & $21,07 \mathrm{a}$ & $8,82 \mathrm{a}$ & $2,89 \mathrm{a}$ & $6,5 \mathrm{a}$ & $0,9660 \mathrm{a}$ \\
$\mathbf{4}$ & $10,93 \mathrm{a}$ & $14,00 \mathrm{a}$ & $20,61 \mathrm{a}$ & $8,42 \mathrm{a}$ & $3,14 \mathrm{a}$ & $6,4 \mathrm{a}$ & $0,8721 \mathrm{a}$ \\
$\mathbf{5}$ & $9,72 \mathrm{a}$ & $12,05 \mathrm{a}$ & $20,28 \mathrm{a}$ & $7,80 \mathrm{a}$ & $2,62 \mathrm{a}$ & $6,3 \mathrm{a}$ & $0,8159 \mathrm{a}$ \\
$* \mathbf{C V} \%$ & 19,30 & 27,02 & 9,33 & 11,73 & 14,75 & 8,46 & 23,27 \\
\hline
\end{tabular}

Nota: *CV: coeficiente de variância.

Observa-se na Tabela 2 que não ocorreu diferenças significativas a 5\% de probabilidade pelo teste de Tukey de todas as variáveis analisadas.

Na Tabela 3 é mostrada a população dos micro-organismos presentes no rabanete.

Tabela 3. Resultados obtidos para UFC $\mathrm{g}^{-1}$ de mesófilos, NMP $\mathrm{g}^{-1}$ de coliformes termotolerantes e ausência em $25 \mathrm{~g}$ de Salmonella.

\begin{tabular}{|c|c|c|c|c|c|}
\hline \multirow{2}{*}{ Micro-organismos } & \multicolumn{5}{|c|}{ Diluições } \\
\hline & 1 & 2 & 3 & 4 & 5 \\
\hline Mesófilos (UFC.g $\mathrm{g}^{-1}$ ) & $1,9 \times 10^{6}$ & $1,9 \times 10^{6}$ & $1,9 \times 10^{6}$ & $1,9 \times 10^{6}$ & $1,9 \times 10^{6}$ \\
\hline Coliformes termotolerantes (NMP g ${ }^{-1}$ ) & $\leq 3$ & $\leq 3$ & $\leq 3$ & $\leq 3$ & $\leq 3$ \\
\hline Salmonella (ausência em 25g) & ausente & ausente & Ausente & ausente & ausente \\
\hline
\end{tabular}

Verifica-se, na Tabela 3, que os valores encontrados estão dentro dos padrões estabelecidos pela Resolução ANVISA $n^{0} 12$ (Brasil, 2001), que preconiza a ausência de Salmonella em 25 gramas e a população máxima de $10^{3} \mathrm{NMP}^{-1}$ de coliformes termotolerantes.

Os resultados obtidos corroboram com os obtidos por Carvalho et al. (2013) que também obtiveram ausência de Salmonella e coliformes menores que 3 NMP g-1, no estudo da irrigação de girassol com efluente tratado no mesmo sistema de lagoas de estabilização.

\section{CONCLUSÃO}

O efluente mostrou-se viável na irrigação da cultura do rabanete não apresentando diferença entre os tratamentos com relação às variáveis agronômicas e, principalmente, os valores encontrados dos patógenos serem aceitos pela Resolução ANVISA n $^{\mathbf{1}} 12$ (Brasil, 2001). 


\section{REFERÊNCIAS}

ALLEN, R. G. et al. Crop evapotranspiration - Guidelines for computing crop water requirements. Rome: FAO, 1998. (FAO Irrigation and Drainage, 5).

ASANO, T. et al. Water reuse, issues, technologies, and applications. New York: Metcalf \& Eddy/AECOM; McGraw Hill, 2007.

BEUCHAT, L. R. Ecological factors influencing survival and growth of human pathogens on raw fruits and vegetables. Microbes and Infection, v. 4, p. 413-423, 2002. http://dx.doi.org/10.1016/S1286-4579(02)01555-1

BRACKETT, R. E. Incidence, contributing factors, and control of bacterial pathogens in produce. Postharvest Biology and Technology, v. 15, p. 305-311, 1999. http://dx.doi.org/10.1016/S0925-5214(98)00096-9

BRASIL. Agência Nacional de Vigilância Sanitária. Resolução RDC no 12, de 02 de janeiro de 2001. Aprova o Regulamento Técnico sobre padrões microbiológicos para alimentos. Diário Oficial [da] União; Poder Executivo, de 10 de janeiro de 2001

CARDOSO, A. I. I.; HIRAKI, H. Avaliação de doses e épocas de aplicação de nitrato de cálcio em cobertura na cultura do rabanete. Horticultura Brasileira, Brasília, v. 19, n. 3, p. 196-199, novembro 2001.

CARVALHO, R. S.; SANTOS FILHO, J. S.; SANTANA, L. O. G.; GOMES, D. A.; MENDONÇA, L. C.; FACCIOLI, G. G. Influência do reuso de águas residuárias na qualidade microbiológica do girassol destinado à alimentação animal). Revista Ambiente \& Água, v. 8, n. 2, p. 157-167, 2013. http:/dx.doi.org/10.4136/ambiagua. 1116

DALTRO FILHO, J. Saneamento ambiental: doença, saúde e o saneamento da água. São Cristóvão: UFS, 2004. 332 p.

DOORENBOS, J.; PRUITT, J. O. Guidelines for predicting crop water requeriments. Rome: FAO, 1977. 179 p. (FAO Irrigation and Drainage, 24).

DUARTE, A. Reuso de água residuária tratada na irrigação da cultura do pimentão (Capsicum annun L). 2006. 187f. Tese (Doutorado) - Escola Superior de Agricultura Luiz de Queiroz, Piracicaba, 2006.

DUARTE, A. S.; AIROLDI, R. P. S.; FOLEGATTI, M. V.; BOTREL, T. A.; SOARES, T. M. Efeitos da aplicação de efluente tratado no solo: $\mathrm{pH}$, matéria orgânica, fósforo e potássio. Revista Brasileira de Engenharia Agrícola e Ambiental, v. 12, n. 3, p. 302-310, 2008. http://dx.doi.org/10.1590/S1415-43662008000300012

FARIA, M. A. Simpósio de manejo de irrigação. Poços de Caldas: [s.n.], 1998. 367 p.

HESPANHOL, I. Potencial de reuso de água no Brasil: agricultura, indústria, município e recarga de aquíferos. In: MANCUSO, P. C. S.; SANTOS, H. F. (Eds.). Reuso de água. Barueri: Manole, 2003. p. 37-95.

HESPANHOL, I. Potencial de reuso de água no Brasil: agricultura, indústria, municípios, recarga de aquíferos. Revista Brasileira de Recursos Hídricos - RBRH, Porto Alegre, ed. comemorativa, v. 7, n. 4, p. 75-97, dez. 2002. 
KING, A. D.; MAGNUSON, J. A.; TOROK, T.; COODMAN, N. Microbial flora and storage quality of partially processed lettuce. Journal of Food Science, v.56, p.459-461, 1991.

KORNACKI, J. L.; JOHNSON, J. L. Enterobacteriaceae, Coliforms, and Escherichia coli as quality and safety indicators. In: DOWNES, F. P.; ITO, K. Compendium of methods for the microbiological examination of foods. 4. ed. Washington: American Public Health Association, 2001. cap. 8, p. 69-82.

MEDEIROS, S. S.; SOARES, A. A.; FERREIRA, P. A.; NEVES, J. C. L.; SOUZA, J. A. Utilização de água residuária de origem doméstica na agricultura: estudo do estado nutricional do cafeeiro. Revista Brasileira de Engenharia Agrícola e Ambiental, v. 12, n. 2, p. 109-115, 2008. http://dx.doi.org/10.1590/S1415-43662008000200001

MORTON, D. R. Aerobic plate count. In: DOWNES, F. P.; ITO, K. Compendium of methods for the microbiological examination of foods. 4. ed. Washington: American Public Health Association, 2001. cap. 37, p. 63-67.

NGUYEN-THE, C.; CARLIN, F. The microbiology of minimally processed fresh fruits and vegetables. Critical Reviews in Food Science and nutrition, v. 34, p. 371-401, 1994.

PELCZAR JR., M. J; CHAN, E. C. S.; KRIEG, N. R. Microbiologia: conceitos e aplicações. 2. ed. São Paulo: McGraw-Hill, 1997. v. 2, cap. 30, p. 372-397.

RAMIRO, T. H. S.; BARBOSA JUNIOR, A. M.; DOLABELLA, S. S.; KATAGIRI, S.; MENDONÇA, L. C. Remoção de patógenos em sistema de lagoas de estabilização. In: ENCONTRO DE INICIAÇÃO CIENTÍFICA, 22., 2012, São Cristóvão. Anais... São Cristóvão: UFS, 2012.

SWANSON, K. M. J.; PETRAN, R. L.; HANLIN, J. H. Culture methods for enumeration of microorganisms. In: DOWNES, F. P.; ITO, K. (Eds.). Compedium of methods for the microbiological examination of foods. 4. ed. Washington: American Public Health Association, 2001. cap. 6, p. 53-62.

WORLD HEALTH ORGANIZATION - WHO. Wastewater use in agriculture. In:

Guidelines for the safe use of wastewater, excreta and greywater. Genebra, 2006. v. 2. 